\title{
Palaeoecology and sea level changes: Decline of mammal species richness during late Quaternary island formation in the Montebello Islands, north-western Australia
}

\author{
Cassia J. Piper and Peter M. Veth
}

\begin{abstract}
Changes in sea level and the formation of islands impact the distributions and abundances of local flora and fauna, with palaeo-environmental investigations providing a context for biological conservation. The palaeo-environmental knowledge of the north-west of Australia during the late Quaternary is sparse, particularly the impact of island formation on local faunas.

In 1991 and 1993 Peter Veth and colleagues conducted archaeological surveys of the Montebello Islands, an archipelago situated $70-90 \mathrm{~km}$ from the present-day coastline of north-west Australia. A group of three caves were found during this survey on the eastern side of Campbell Island. Two of the caves, Noala and Hayne's Caves, were analysed by Veth and colleagues in the early 1990s; the last cave, Morgan's Cave, remained unanalysed because it contained negligible archaeological material. It provides an opportunity to refine the interpretation of palaeo-environmental conditions, further information on the original pre-European fauna of the north-west shelf, the formation of the islands due to sea level rise, and the impact of sea level rise on local faunas.

The fossil fauna assemblage of Morgan's Cave was sorted, identified to the lowest taxonomic level possible, and counted for analysis on relative abundance for paleoenvironmental interpretation. There are marked patterns of species loss and changing relative abundances in certain species, consistent with island formation due to sea level rise. This palaeoecological interpretation can be used in conservation efforts on nearby Barrow Island, a Class A ecological reserve, and management of faunas in conservation reserves and on islands.
\end{abstract}

Cassia J. Piper. Department of Earth and Planetary Sciences, Western Australian Museum, 49 Kew Street, Welshpool,6101. cassia.piper@gmail.com

Peter M. Veth. Indian Oceans Institute, University of Western Australia, Perth, WA 6009.

Peter.Veth@uwa.edu.au

Piper, Cassia J. and Veth, Peter M. 2021. Palaeoecology and sea level changes: Decline of mammal species richness during late Quaternary island formation in the Montebello Islands, north-western Australia. Palaeontologia Electronica, 24(2):a20. https://doi.org/ $10.26879 / 1050$

palaeo-electronica.org/content/2021/3366-palaeoecology-and-rising-seas

Copyright: May 2021 Society of Vertebrate Paleontology.

This is an open access article distributed under the terms of the Creative Commons Attribution License, which permits unrestricted use, distribution, and reproduction in any medium, provided the original author and source are credited. creativecommons.org/licenses/by/4.0 
Keywords: palaeoecology; species-area; Quaternary; island biogeography; sea level rise; small mammal fauna

Submission: 9 December 2019. Acceptance: 15 May 2021.

\section{INTRODUCTION}

During the Quaternary period, climates have cycled between glacial and interglacial phases with a periodicity of some 100 k.y. (Hays et al., 1976; Anderson et al., 2013; Rial et al., 2013; Mannion et al., 2014). At glacial maxima, approximately $5.5 \%$ of the world's water was trapped in ice, compared to only $1.7 \%$ today (Williams 1993; Gibbard and van Kolfschoten, 2004). This resulted in sea levels falling over $120 \mathrm{~m}$ below present, uncovering most continental shelves (Williams, 1993; Anderson et al., 2013; Denniston et al., 2013). As climate warmed at each glacial termination, trapped waters were returned to the oceans causing sea levels to rise, changing exposed plains into seabed and upland areas into islands.

Changes in sea level, land area, and climate impact the distributions and abundances of fauna and flora (Pearson and Dodson, 1993; Mayhew et al., 2012; Anderson et al., 2013; Mannion et al., 2014). The species found in late Quaternary deposits are usually identical to today's extant taxa, the ecology of which is relatively well documented, enabling palaeo-environmental interpretations to be applied with greater confidence (Andrews and Cook, 1990; Birks, 1996; Lyman, 2006; Vegas-Vilarrúbia et al., 2011). These inferred similarities rely on the assumption that species did not adapt to rapid climate change, and instead respond by altering their geographic ranges or abundances by moving into more suitable areas, and becoming less abundant, or indeed becoming extinct, in unsuitable areas (Davis and Shaw, 2001; Vegas-Vilarrúbia et al., 2011; Williams et al., 2011; Lyman, 2012a). Such investigations can inform present-day biological conservation and wildlife management practises, by providing examples of normal background fluctuation in biodiversity, as well as top-down and bottom-up processes and help model for the future effects of climate change (Birks, 1996; Pickett, 1997; Lyman, 2006; Bilney et al., 2010; Terry, 2010; Vegas-Vilarrúbia et al., 2011; Williams et al., 2011; Lyman, 2012a).

The accumulation of biotic remains in a wide variety of geographical areas has significantly contributed to global knowledge of Quaternary environments (Pearson and Dodson, 1993; Birks,
1996; Pearson et al., 1999; Davis and Shaw, 2001; Pokines et al., 2011; Vegas-Vilarrúbia et al., 2011; Lyman, 2012a; McDowell, 2013). Small mammal faunas, such as those accumulated by owls in caves and rock shelters, provide an important resource for interpreting the ecology of past environments (Andrews and Cook, 1990; Kusmer, 1990; Terry, 2010; Bilney, 2012). The source caves of these faunas contain accumulations from predator catchments, and by comparing these with fossil or modern assemblages, changes in climate and the ranges of species over time can be identified. The richness of species and their relative abundances in past faunal assemblages may be climatically informative (Andrews and Cook, 1990; Kusmer, 1990; Terry, 2010; Bilney, 2012).

The study of islands has had a significant and enduring impact on both conservation biology and our knowledge of palaeobiogeography in Australia. Studies have included elucidating the effects of fragmentation, isolation, and extinction of both ancient and extant faunas, determining the importance of appropriate sizes for natural reserves, and providing insights into genetic diversity, evolution, and conservation in extant faunas (Mills et al., 2004; Barnosky et al., 2005; Laurance, 2010; Moro and Lagdon, 2013; Gibson, 2014; McDowell et al., 2015). Much of the Australian north-west shelf was exposed during the Last Glacial Maximum (LGM), which lasted from 26 to $19 \mathrm{ka}$, after which rapid deglaciation began, causing sea levels to rise and the shelf to be flooded by c. 7 ka (Veth et al., 2007; Reeves et al., 2013). There is little palaeo-environmental information for north-western Australia. Excavations in the Cape Range Peninsula (Morse, 1993; Przywolnik, 2005) yielded few mammal remains. Baynes and McDowell (2010) conducted a survey on the original mammal fauna of the Pilbara region, but all their sites were on the mainland. As a result, knowledge of the Quaternary palaeoenvironments from this region is sparse (Veth et al., 2007), particularly the faunal response to the impact of island formation.

However, on the Montebello Islands (Figures 1 and 2), Veth and colleagues (Veth, 1993, 1995; Veth et al., 2007) found and excavated archaeological deposits from one group of three small caves on a short limestone peninsula on the eastern side 


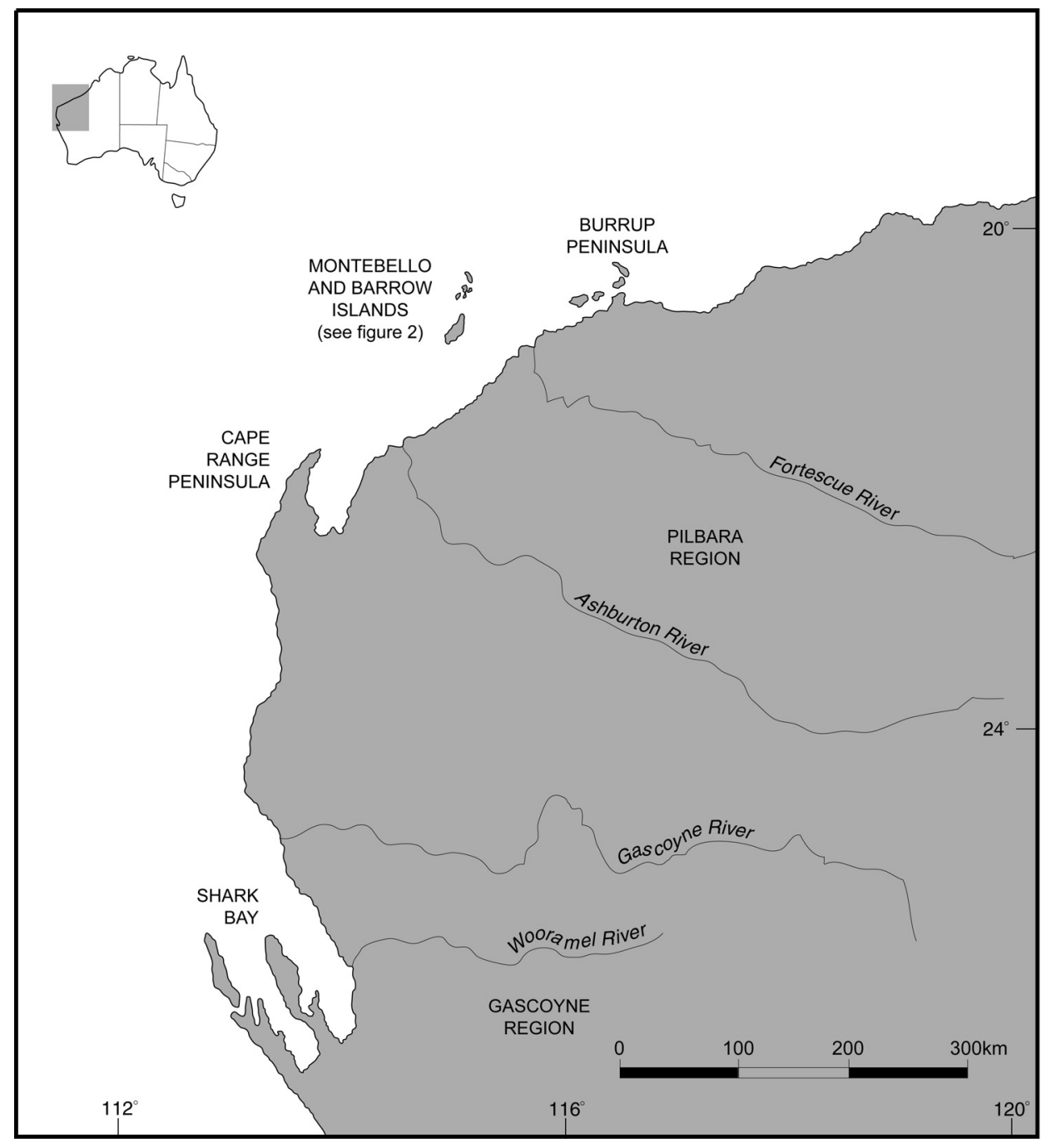

FIGURE 1. Map of the northwest coast of Western Australia showing the relation between the Montebello and Barrow Islands and Cape Range peninsula.

of Campbell Island. He named the sites Noala, Hayne's, and Morgan's Caves. Noala and Hayne's Caves were rich in cultural remains and were analysed in detail over the next decade (Veth et al., 2007). These excavations from the Montebello Islands, as well as those from Barrow Island and Cape Range on the north-west shelf, record two phases of island formation; firstly, the formation of the Barrow and Montebello "super-island" around 8 k.y.a. and then the separation of these two by around 7 k.y.a. (Veth et al., 2007) (Figure 2).

The species-area relationship is one of the most fundamental patterns in ecology worldwide and is evident even in palaeontological deposits (Arrhenius, 1921; Hope et al., 1977; Lomolino, 2000; Barnosky et al., 2005). While Morgan's Cave was not originally analysed due to the lack of cul- tural material, the researchers did recover considerable quantities of non-economic faunas. These provide an opportunity to further our understandings of the original, pre-European fauna of the north-west shelf, the formation of the islands due to sea level rise, and the impact on the local fauna from sea level rise.

Excavations in caves and rock shelters on other islands, both in Australia and around the world, are continually expanding our knowledge of island biogeography. Our current analysis of the Morgan's Cave faunal deposit contributes specifically to the studies of the effect of insularisation on ancient faunas. These insights are directly relevant to local conservation science and interventions including species reintroductions. This palaeoecological interpretation can be used in conservation 
efforts on nearby Barrow Island, a Class A ecological reserve with a unique island ecosystem (Moro and Lagdon, 2013).

\section{MATERIALS AND METHODS}

\section{Study Site}

The Montebello Islands, also known as the Monte Bello Islands, comprise 15 named islands and 170 islets and rocks off the north-west coast of Western Australia (Burbidge et al., 2000; Veth et al., 2007) (Figures 1 and 2). Along with Barrow

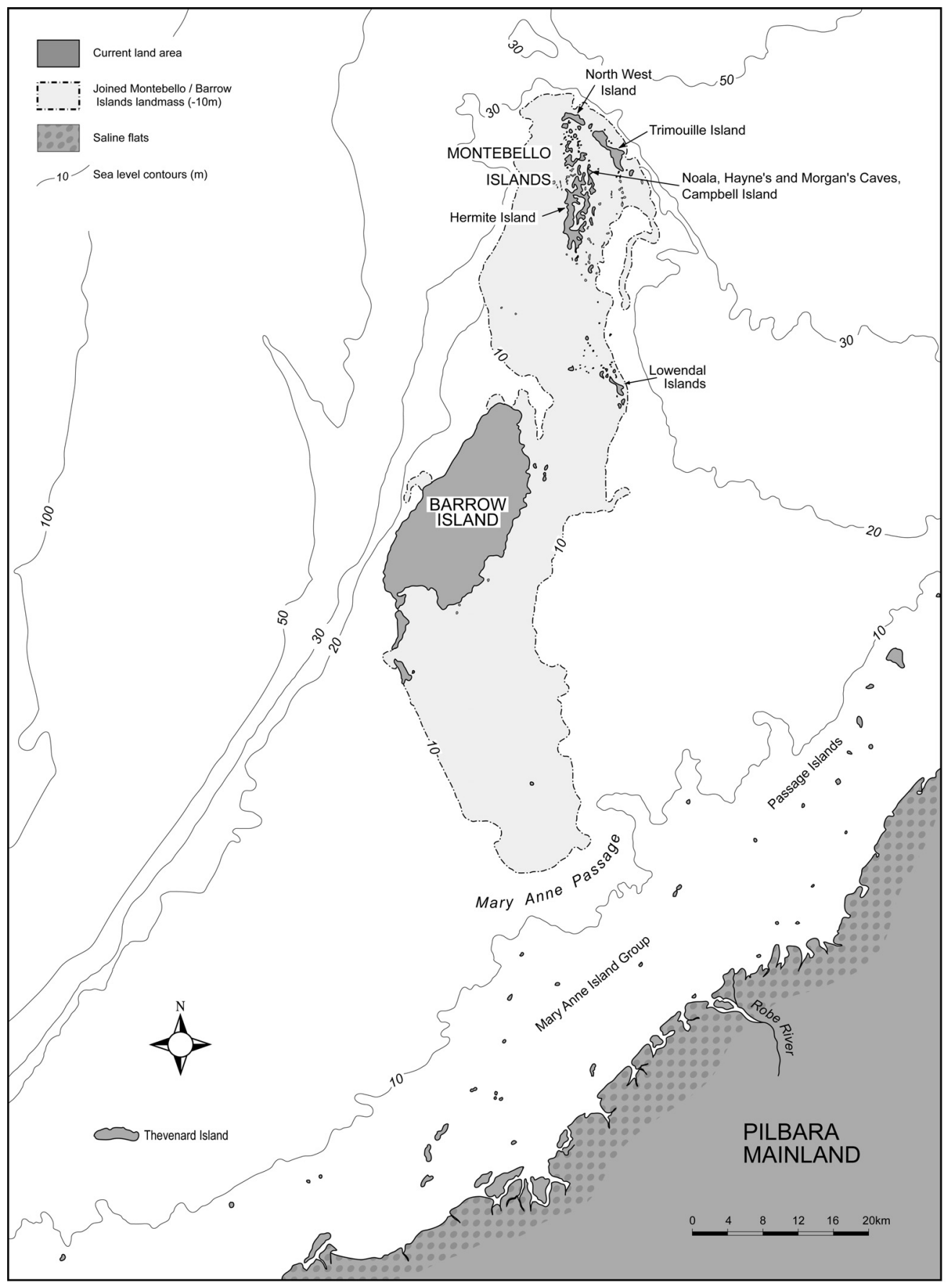

FIGURE 2. A close-up map of Barrow and Montebello Islands, showing bathymetry of the area around the islands. The $10 \mathrm{~m}$ isohyet shows the outline of the "super-island", created when sea levels cut off the islands from the mainland and discussed below. 


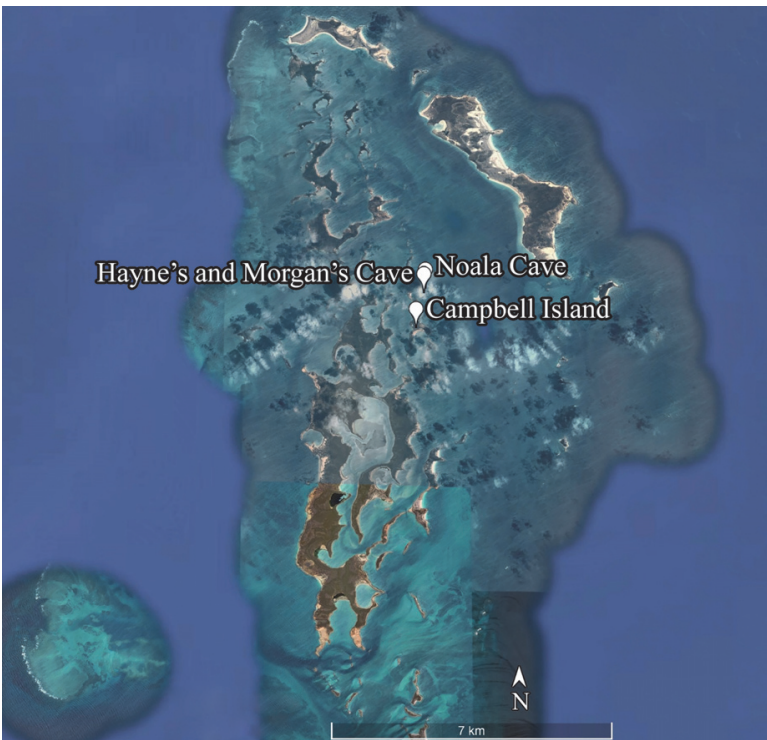

FIGURE 3. Google Earth@ (2020) image of Campbell Island within the Montebello Island group.

Island, $20 \mathrm{~km}$ south, and Cape Range peninsula, $250 \mathrm{~km}$ to the south-west, they are part of the same uplifted block of Carnarvon Basin marine limestone (van de Graaff et al., 1982; Hocking et al., 1987; Hickman and Strong, 2003). The climate is characterised as arid and sub-tropical, with warm temperatures ranging from $24^{\circ} \mathrm{C}$ to $35^{\circ} \mathrm{C}$ throughout the year, and low and unpredictable rainfall of approximately $200 \mathrm{~mm}$ per annum (Hill, 1955; Burbidge et al., 2000; Veth et al., 2007; Moro and Lagdon, 2013).

\section{Noala and Hayne's Caves}

Noala, Hayne's, and Morgan's Caves preserved the only surviving stratified deposits found on the islands (Figures 2 and 3). Noala Cave lies on the northern side of the peninsula, and Hayne's and Morgan's Caves on the southern side (Figure 4). Three test pits were excavated in Noala Cave and five in Hayne's Cave (Veth, 1993; Veth et al., 2007). Noala and Hayne's Caves were analysed in the 1990s, and the findings were published in Veth et al (2007), but the material from Morgan's Cave remained uninvestigated due to it containing negligible archaeology (Veth et al., 2007).

\section{Morgan's Cave}

In the 1990s, the Morgan's Cave fauna was initially examined by Ken Aplin, but not studied in detail (Veth et al., 2007).

The Cave comprises a single chamber that is almost entirely enclosed due to the partial collapse

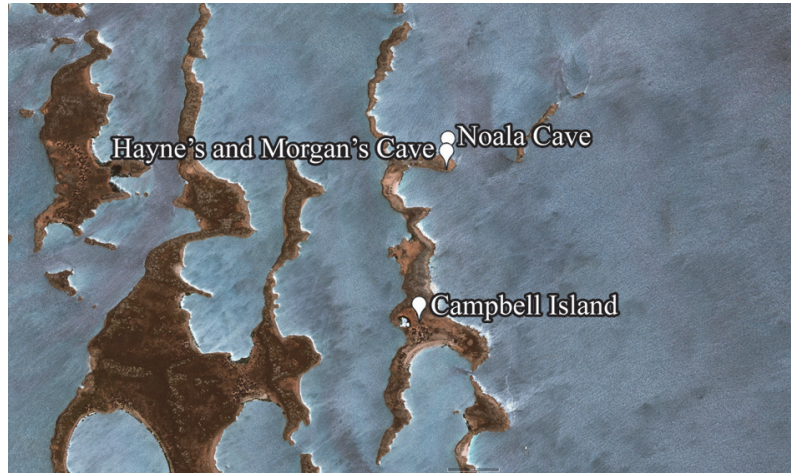

FIGURE 4. Google Earth@ (2020) image showing approximate positions of the three caves on the peninsula surveyed by Veth.

of the limestone roof (Veth, 1993). A $1 \mathrm{~m} \times 1 \mathrm{~m}$ test pit was excavated at the western end of the chamber, where bone density seemed to be greatest at the surface (Veth, 1993). This excavation was done methodically but was restricted to one test pit due to the lack of apparent cultural materials. This was considered unsurprising as the entrance is similar to a pitfall cave entrance rather than a rock shelter and would have been difficult for humans to access.

Excavated materials from spits one to seven were passed through nested $6 \mathrm{~mm}$ and $3 \mathrm{~mm}$ sieves. Spit depth ranged between 30 and $45 \mathrm{~mm}$ (Table 1).

Below spit seven, a $50 \mathrm{~cm} \times 50 \mathrm{~cm}$ sondage was continued in the north-west corner of the main

TABLE 1. Spit depths and cumulative depth of the Morgan's Cave deposit conducted by Veth (1993).

\begin{tabular}{ccc}
\hline $\begin{array}{c}\text { Morgan's } \\
\text { Cave spit } \\
\text { number }\end{array}$ & $\begin{array}{c}\text { Depth of spit } \\
(\mathbf{m m})\end{array}$ & $\begin{array}{c}\text { Cumulative depth spits } \\
\text { below surface level } \\
(\mathbf{m m})\end{array}$ \\
\hline 1 & 40 & 40 \\
2 & 30 & 70 \\
3 & 30 & 100 \\
4 & 30 & 130 \\
5 & 35 & 165 \\
6 & 45 & 210 \\
7 & 40 & 250 \\
8 & 50 & 300 \\
9 & 50 & 350 \\
10 & 50 & 400 \\
11 & 60 & 460 \\
12 & 70 & 530 \\
13 & 60 & 590 \\
\hline
\end{tabular}


square. Only a $6 \mathrm{~mm}$ sieve was used here, and spits were 50 to $70 \mathrm{~mm}$ deep, due to the presence of large boulders. Mammal bone was recovered down to bedrock at a depth of $590 \mathrm{~mm}$ below surface level (Veth, 1993). The screen residues from each spit were bagged and labelled.

No detailed plans or cave drawings were made due to the lack of cultural materials.

\section{Sample Preparation and Identification for Morgan's Cave}

The faunal remains from Morgan's Cave required more detailed examination for accurate identifications. The $3 \mathrm{~mm}$ screen residues for Morgan's Cave were subsequently wet screened through a $0.7 \mathrm{~mm}$ sieve with running water to remove the fine sediment and air dried. They were then manually sorted into rock, shell, and bone, with the bone material being further sorted into identifiable teeth and jaws and unidentifiable fragments. The shell material was sorted into terrestrial and marine molluscs, and bird eggshell, for future analyses. The very sparse $6 \mathrm{~mm}$ residues from spits one to seven were also examined, but none contained identifiable cultural material. The whereabouts of the $6 \mathrm{~mm}$ residues from spits eight to 13 of Morgan's Cave are currently unknown (P. Veth, personal commun., 2020).

After initial sorting, the residues were dry screened through $1.63 \mathrm{~mm}$ sieve to divide them into coarser and finer fractions for ease of sorting. They were cleaned separately in an ultrasonic cleaner for an hour to break down cemented sand and hard clay. As it was unknown whether the cleaner would damage specimens, this was only done after initial sorting, and with small batches being put through the cleaner one at a time. These steps were taken in an effort to minimise any damage to the specimens in the cleaner as much as possible.

The cleaned residues were then washed through a $0.5 \mathrm{~mm}$ sieve, air dried, and re-sorted to obtain as much identifiable bone as possible. The bones and the shells initially classified as unidentifiable were also cleaned ultrasonically, air dried, and re-sorted. Much of the material was covered in calcareous cement, particularly the tooth cusps, which had to be cleaned with the tip of an entomo- logical pin or a scalpel. Cleaning specimens, both ultrasonically and with a pin, enabled diagnostic features to be retained with identifications made on specimens that might not have been identifiable beforehand.

After each spit was processed, the mammal teeth and jaws were identified to the lowest taxonomic level possible by comparison with specimens in the Western Australian Museum vertebrate palaeontology and modern mammal collections, as well as notes from Appendix III of Baynes (1979). Nomenclature followed van Dyck and Straham (2008). The identified material was then counted for each spit, and the counts for each spit and species organised in a spreadsheet. This was used to easily calculate and obtain figures for minimum number of individuals (MNI) and number of identified specimens (NISP).

The identified mammal remains in a bulk surface sample owl pellet accumulation from a cave on Barrow Island were also analysed to obtain MNI and NISP values for modern-day abundances of the extant small mammal populations.

\section{Radiocarbon Dating for Morgan's Cave}

Noala and Hayne's Cave were dated in the 1990s, however, Morgan's Cave needed additional radiocarbon dates to aid in the interpretation of the fauna. There was no charcoal recovered with depth in the excavation. Instead, bone samples from Morgan's Cave were prepared for radiocarbon dating. Spirally-fractured fragments and other larger pieces of non-porous marsupial bone weighing $1-5 \mathrm{~g}$, sufficient for AMS dating, were picked out with forceps to avoid contamination (Table 2). Each sample was placed in a zip lock polythene bag, inside another zip lock bag that contained the label to ensure that the paper of the label did not contaminate the bone. The samples were securely packaged and submitted to the Radiocarbon Dating Laboratory at the University of Waikato, Hamilton, New Zealand.

\section{Suitability for Multivariate Analysis}

Rarefaction curves were generated using PAST v3.0 (Hammer et al. 2001) for each spit in the Morgan's Cave deposit from the fossil mammal NISP data. These were used to assess whether

TABLE 2. Weights of bone samples from Morgan's Cave submitted to the University of Waikato for radiocarbon dating. Bone samples were made up of spirally-fractured fragments and other large pieces of non-porous bone.

\begin{tabular}{lccccccc}
\hline Morgan's Cave spit number & 1 & 2 & 3 & 4 & 5 & 6 & 7 \\
Bone weight $(\mathbf{g})$ & 3.30 & 4.72 & 5.30 & 5.07 & 6.75 & 6.67 & 8.23 \\
\hline
\end{tabular}


the sample sizes for each spit are large enough for valid statistical tests between spits.

\section{Sample to Redundancy (STR) Curve}

A species accumulation curve, or sample to redundancy curve (STR curve), for Morgan's Cave was generated by comparing cumulative NISP to cumulative species identified, with species being added as they are identified as the deposit gets larger and the total number of specimens increases (Lyman and Ames, 2004; 2007; Gotelli and Colwell, 2001; Mitchell et al., 2016). This is used to assess whether larger samples would have yielded specimens of rarer species, or if samples were only adding more specimens of already identified species.

\section{Spindle Diagram}

A spindle diagram was made to mimic the deposit, with species found in spit one at the top of the plot, and species found in the bottom of the deposit at the bottom of the plot. All species found in three or more spits in Morgan's Cave, plus all the mammals recorded in the Barrow Island owl pellet material, were used to generate a spindle plot in PAST v3.0 (Hammer et al., 2001). This was to minimise overcrowding on the graph and highlight the species which could interpret the most information.

\section{RESULTS}

\section{Radiocarbon Dating}

Nine uncalibrated radiocarbon dates were obtained from Hayne's Cave and four radiocarbon dates from Noala Cave (Veth et al. 2007). These were mainly based on marine mollusc shell. From the assay, Veth (1993, 1995; Veth et al., 2007) argued that Noala Cave was briefly occupied at about 27 k.y.a. and was then re-occupied from 12.5 k.y.a. to 8.7 k.y.a. In contrast, Hayne's Cave was occupied after Noala Cave was abandoned, over a short time span from 8.3 k.y.a. to 7.5 k.y.a. (Veth et al. 2007).

The dating laboratory reported that there was no collagen left in any of the bone samples from Morgan's Cave (Table 2), so no ages could be determined from that site (F. Petchey in. litt., 20 Mar 2014).

\section{Fauna}

Thirty-one mammal species were identified from Square 1A in Noala Cave. Eighteen of the 31 mammal species are likely to represent the remains of disaggregated Tyto alba pellets, perhaps with some material derived from natural deaths (Veth et al., 2007). The fauna included 12 species of rodents (Muridae) (Veth et al., 2007), of which only three are found on Barrow Island today, however, all are recorded from recent cave deposits in nearby Cape Range and/or in the Pilbara (Baynes and Jones, 1993; Baynes and McDowell, 2010).

The mammalian fauna from Hayne's Cave was similar to that found in Noala Cave, with the exception of three rodents and a variety of small dasyurid species, which were only recorded from Noala Cave, and the wallaby Onychogalea unguifera. Two rodents were confined to the lower spits of Noala Cave; both species are associated with non-sandy substrates (Veth et al., 2007).

The Morgan's Cave fossil mammal fauna comprises 36 species (Table 3), and shares many elements with those recorded from Noala and Hayne's Caves (Veth et al., 2007). Sample sizes for each spit decline towards the surface of the deposit, as shown by total NISP (Table 3).

The mammalian carnivores occur in low relative abundances in the deposit. Thylacinus cynocephalus is present in spits four and six. Dasyurids and other small carnivores are present in most spits, although many of the smaller remains are too fragmented to identify to species level. Planigale $\mathrm{sp}$. is quite common on Barrow Island today but was only found in spit five in Morgan's Cave. The bat Macroderma gigas is only present in spits seven, six and five.

Isoodon auratus was recorded in all spits, occurring in increasing relative abundances towards the top of the deposit, and is widely present on Barrow Island today.

The majority of the larger marsupials recorded from the Morgan's Cave deposit are species still present on Barrow Island today, with the addition of the sand plain species Lagorchestes hirsutus, present in spits four to seven. The desert species Onychogalea lunata is also present, in slightly lower abundances than $L$. hirsutus.

Rodents are the most diverse group with 15 species recorded. Sand plain specialists such as Notomys alexis, Pseudomys hermannsburgensis and Notomys amplus are present throughout, often in high relative abundances; but so are non-sand plain species, such as Rattus tunneyi, Pseudomys nanus, Zyzomys argurus, and Notomys longicaudatus. Hydromys chrysogaster is present in the deposit and on Barrow Island now. 
TABLE 3. NISP and relative abundances (\% NISP) for fossil mammal species from the Morgan's Cave test pit and Barrow Island owl pellet (BWI OP) material. "-" indicates species not recorded in a spit. "X" indicates species that are present on Barrow Island (Abbott and Burbidge, 1995) but are not present in the owl pellet material.

\begin{tabular}{|c|c|c|c|c|c|c|c|c|}
\hline & \multicolumn{7}{|c|}{ Morgan's Cave Spit Number } & \multirow[t]{2}{*}{ BWI OP } \\
\hline & 7 & 6 & 5 & 4 & 3 & 2 & 1 & \\
\hline Thylacinus cynocephalus & - & $1(0.38)$ & - & $1(0.48)$ & - & - & - & - \\
\hline Dasycercus sp. indet. & $3(0.74)$ & $4(1.50)$ & $2(0.63)$ & $1(0.48)$ & $1(0.47)$ & $1(0.88)$ & - & - \\
\hline Dasyurus geoffroii & $1(0.25)$ & $3(1.12)$ & $1(0.31)$ & $1(0.48)$ & - & - & - & - \\
\hline Planigale sp. & - & - & $1(0.31)$ & - & - & - & - & $10(5.26)$ \\
\hline Pseudantechinus sp. & $3(0.74)$ & $2(0.75)$ & - & $1(0.48)$ & - & - & - & $27(14.2)$ \\
\hline Sminthopsis sp. indet. & $3(0.74)$ & $1(0.38)$ & $1(0.31)$ & - & $4(1.88)$ & - & - & - \\
\hline Dasyuridae indet. & $3(0.74)$ & $4(1.50)$ & - & $2(0.96)$ & - & - & - & - \\
\hline Isoodon auratus & $10(2.46)$ & $9(3.37)$ & $19(5.98)$ & $24(11.5)$ & $23(10.8)$ & $22(19.3)$ & $11(18.0)$ & $11(5.79)$ \\
\hline Perameles bougainville & $1(0.25)$ & - & $2(0.63)$ & $1(0.48)$ & $4(1.88)$ & - & - & - \\
\hline Macrotis lagotis & - & - & $1(0.31)$ & - & $2(0.94)$ & - & - & - \\
\hline Trichosurus vulpecula & - & $2(0.75)$ & $3(0.94)$ & $4(1.91)$ & $4(1.88)$ & $2(1.75)$ & - & $x$ \\
\hline Bettongia lesueur & $2(0.49)$ & $5(1.87)$ & $5(1.57)$ & $7(3.35)$ & $3(1.41)$ & $2(1.75)$ & - & $x$ \\
\hline $\begin{array}{l}\text { Lagorchestes } \\
\text { conspicillatus }\end{array}$ & $1(0.25)$ & - & $2(0.63)$ & $1(0.48)$ & $1(0.47)$ & $2(1.75)$ & $2(3.28)$ & $x$ \\
\hline Lagorchestes hirsutus & $3(0.74)$ & $5(1.87)$ & $3(0.94)$ & $3(1.44)$ & - & - & - & - \\
\hline Osphrantor robustus & - & - & - & - & - & - & - & $x$ \\
\hline Onychogalea lunata & $2(0.49)$ & $1(0.38)$ & - & - & $1(0.47)$ & $2(1.75)$ & $1(1.64)$ & - \\
\hline Petrogale lateralis & $1(0.24)$ & $1(0.38)$ & $2(0.63)$ & - & - & - & - & $\mathrm{x}$ \\
\hline Microchiroptera indet. & - & - & - & $1(0.48)$ & - & - & - & - \\
\hline Leggadina sp. indet. & - & $1(0.38)$ & $1(0.31)$ & - & - & - & - & - \\
\hline Notomys alexis & $112(27.59)$ & $82(30.7)$ & $95(29.9)$ & $60(28.7)$ & $38(17.8)$ & $6(5.26)$ & $5(8.20)$ & - \\
\hline Notomys amplus & $61(15.02)$ & $29(10.9)$ & $17(5.35)$ & $8(3.83)$ & $2(0.94)$ & $2(1.75)$ & $2(3.28)$ & - \\
\hline Notomys longicaudatus & $10(2.46)$ & $7(2.62)$ & $5(1.57)$ & $4(1.91)$ & $2(0.94)$ & $1(0.88)$ & - & - \\
\hline Pseudomys chapmani & $8(1.97)$ & $4(1.50)$ & $2(0.63)$ & - & - & - & - & - \\
\hline Pseudomys delicatulus & - & $2(0.75)$ & - & $5(2.39)$ & $2(0.94)$ & - & - & - \\
\hline Pesudomys desertor & $6(1.48)$ & $2(0.75)$ & $4(1.26)$ & $2(0.96)$ & - & - & $1(1.64)$ & - \\
\hline Pseudomys fieldi & $8(1.97)$ & $2(0.75)$ & - & - & $1(0.47)$ & $1(0.88)$ & - & - \\
\hline $\begin{array}{l}\text { Pseudomys } \\
\text { hermannsburg. }\end{array}$ & 97 (23.89) & $38(14.2)$ & $63(19.8)$ & $17(8.13)$ & $17(7.98)$ & $1(0.88)$ & $1(1.64)$ & - \\
\hline Pseudomys nanus & $23(5.67)$ & $18(6.74)$ & $51(16.0)$ & $31(14.8)$ & $71(33.3)$ & $51(44.7)$ & $29(47.5)$ & $108(56.8)$ \\
\hline Rattus tunneyi & $37(9.11)$ & $27(10.1)$ & $23(7.23)$ & $23(11.0)$ & $15(7.04)$ & $3(2.63)$ & $1(1.64)$ & - \\
\hline Zyzomys argurus & $3(0.74)$ & $9(3.37)$ & $13(4.09)$ & $11(5.26)$ & $20(9.39)$ & $15(13.2)$ & $8(13.1)$ & $34(17.9)$ \\
\hline Zyzomys pedunculatus & $2(0.49)$ & - & - & - & - & - & - & - \\
\hline Muridae indet. & 82 & 76 & 75 & 48 & 49 & 24 & 13 & - \\
\hline Total NISP & 406 & 267 & 318 & 209 & 213 & 114 & 61 & 190 \\
\hline
\end{tabular}

\section{Suitability for Multivariate Analysis}

Before any multivariate analysis between the spits of Morgan's Cave was carried out, rarefaction curves were generated to determine has been sequenced sufficiently to represent its true diversity. The rarefaction curves for the spits in the Mor- gan's Cave deposit do not tend towards an asymptote, indicating that there are too few specimens to carry out a valid multivariate analysis between spits (Figure 5). Unfortunately, this means that Morgan's Cave needs to be analysed as a 

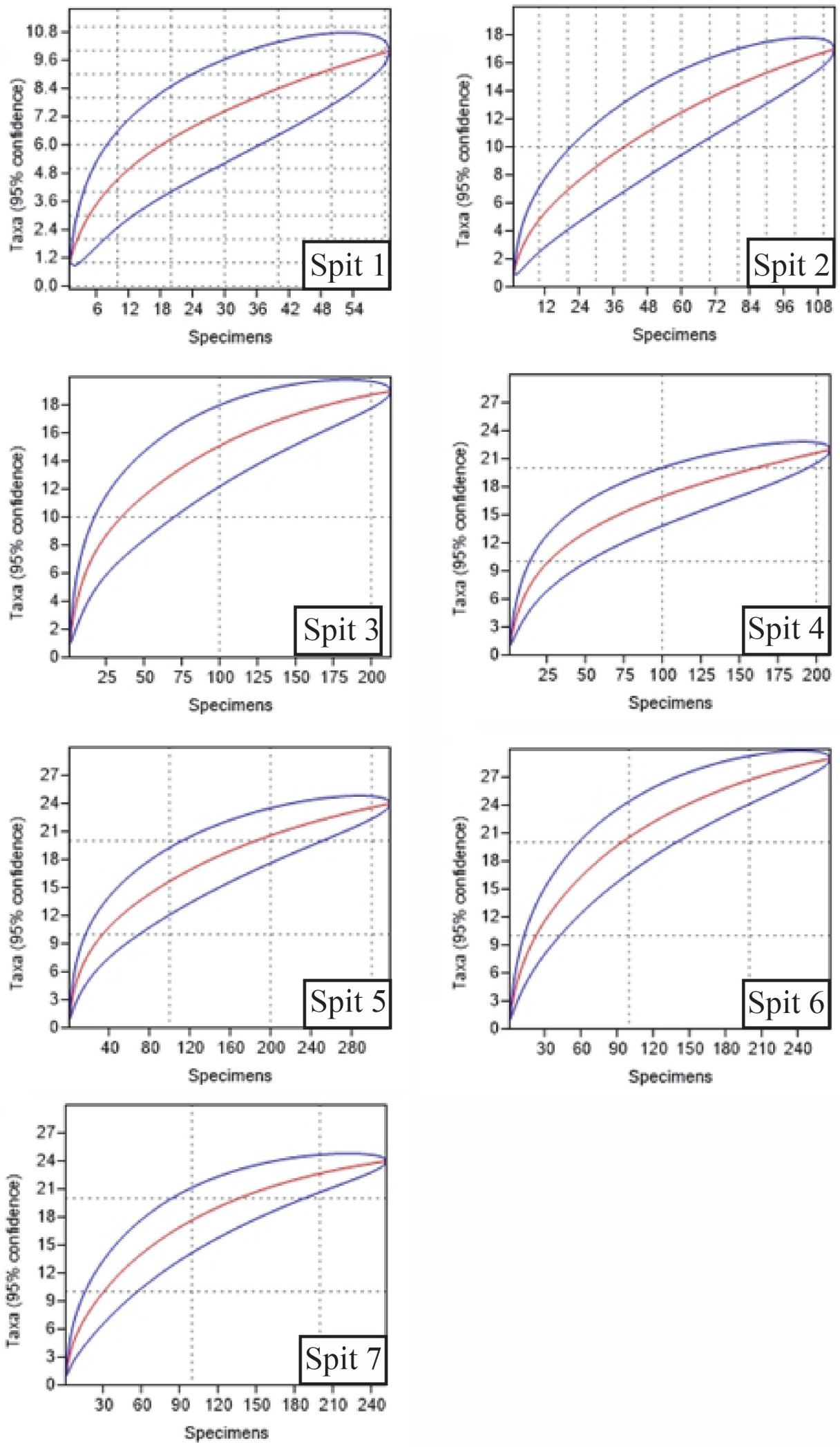

FIGURE 5. Rarefaction Curves for each of the seven spits in Morgan's Cave. 


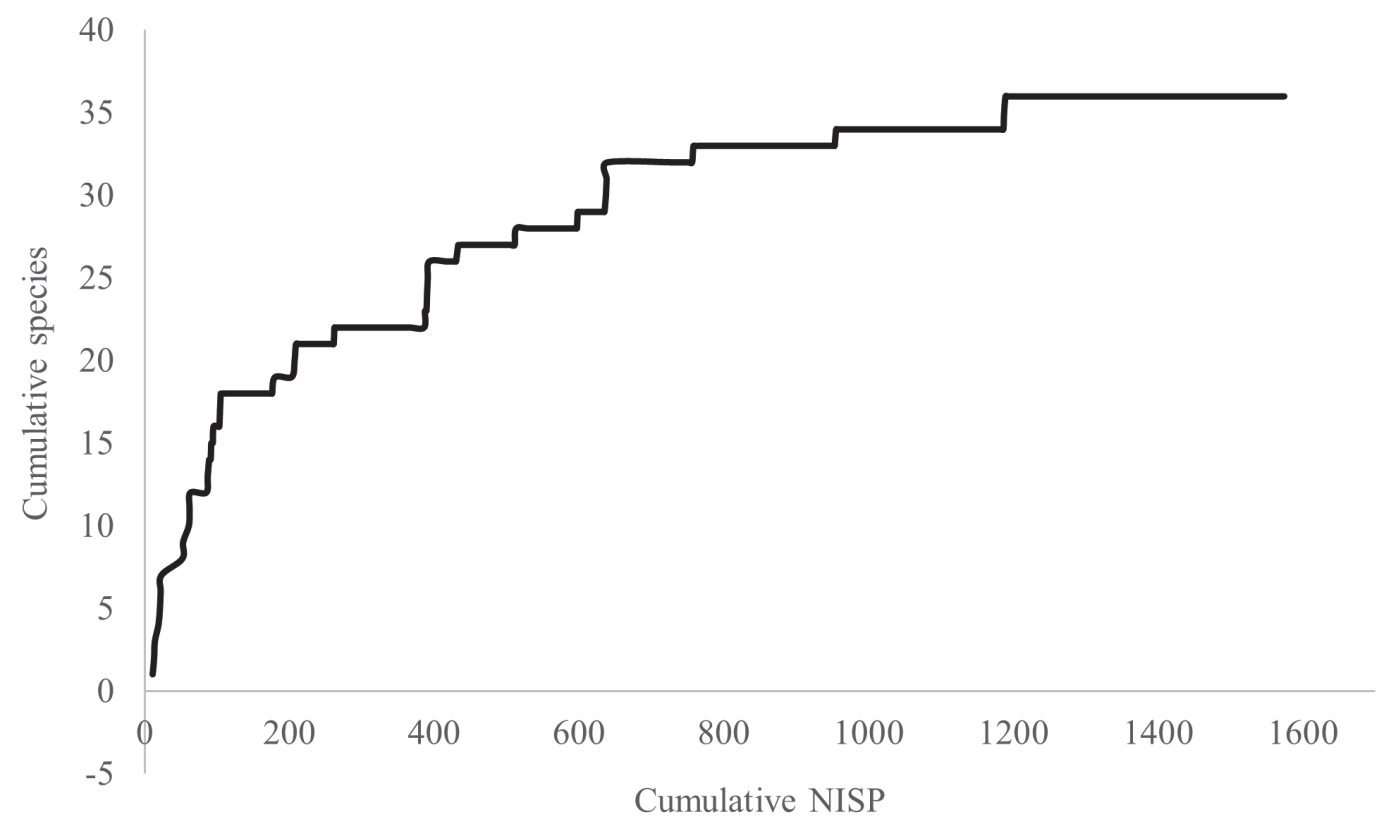

FIGURE 6. Species accumulation curve for Morgan's Cave, showing increasing species with increased sampling effort (cumulative NISP). Further sampling effort could have yielded more species.

whole deposit, as no accurate data can be found from the analysis of individual spits.

\section{Species Accumulation}

The Morgan's Cave deposit comprises a total of 1577 specimens, compared to Square $1 \mathrm{~A}$ from Noala Cave, which registered total NISP of 1096 (Veth et al., 2007). The higher number of specimens recovered from Morgan's Cave is likely due to the extra effort spent in ultrasonically cleaning and resorting the samples, which enabled more identifications to be made, and their non-anthropogenic origin. The graph is starting to level out, with only a few species being added after approximately 1100 specimens were recovered (Figure 6). There is every chance that more species could potentially have been present at the time of deposition, but are not represented in the fauna, impacting the number of species identified in the deposit. These results indicate that Morgan's Cave hasn't been sampled to redundancy and that further recovery is warranted (Lyman and Ames, 2004; 2007; Mitchell et al., 2016).

\section{Spindle Diagram}

The relative abundances for species in Morgan's Cave are relatively stable in spits seven to four, but then strong trends begin to emerge, with major changes in the increasing relative abun- dance of Pseudomys nanus, in particular. Pseudomys nanus and Zyzomys argurus persist on Barrow Island today and show a rising trend that links the Morgan's Cave data to the Barrow Island data, whereas the other species plotted, particularly those adapted to sand plains, start to fall in relative abundance and eventually disappear.

The individual spindles for Morgan's Cave morph into that for Barrow Island (Figure 7). While these two samples were collected using different methods (Morgan's Cave was processed through a $3 \mathrm{~mm}$ sieve, Barrow Island was bulk sampled), they were accumulated by similar means, and can help show the trend of the Morgan's Cave fauna towards the modern-day Barrow Island fauna. Dasyurids are much more abundant in the Barrow Island sample, including Planigale maculata, which is only recorded from one spit in Morgan's Cave.

\section{DISCUSSION}

\section{Radiocarbon Dating}

None of the bone samples submitted for radiocarbon dating from Morgan's Cave contained sufficient collagen for AMS dating, and thus the site remains undated. The lack of collagen in the Morgan's Cave bone samples is probably due to the hot, dry climate of the Montebello Islands. The age range of the deposits can be inferred from the fos- 


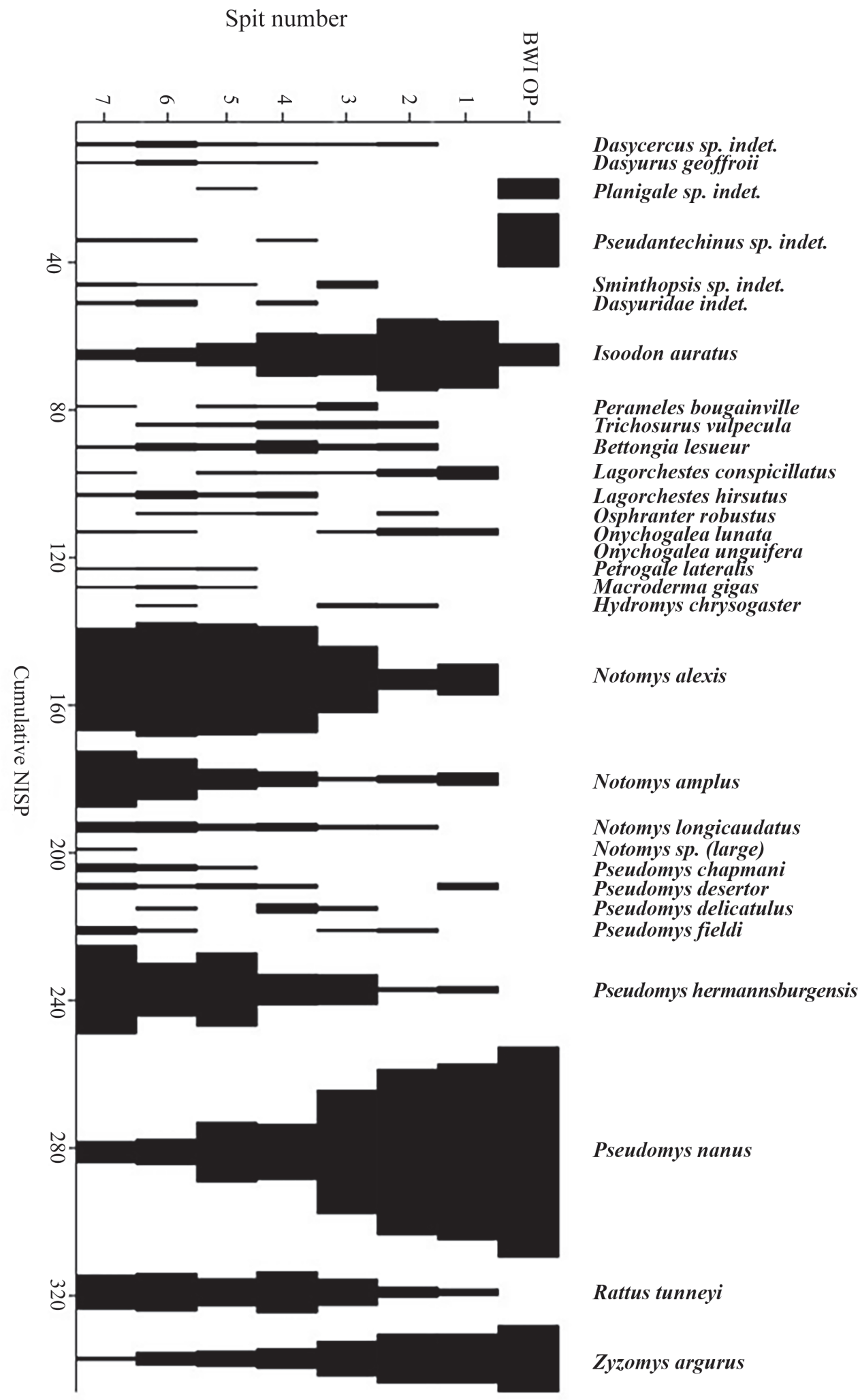

FIGURE 7. Spindle plot of the relative abundances of the species present in three or more spits in the Morgan's Cave deposit, plus all the species recorded in the Barrow Island owl pellet sample, showing the decrease in abundance of sand plain specialists such as Notomys alexis, and the increase in non-sand plain specialists such as Pseudomys nanus. 
sil mammal fauna, combined with sea level rise evidence (discussed below) and the dates from Noala and Hayne's Caves (Veth et al., 2007). These suggest that the fauna from the upper levels of the Morgan's Cave deposit accumulated during the early Holocene to perhaps as late as 7 k.y.a.

\section{Taphonomy}

Veth et al. (2007) interpreted the remains in Noala and Hayne's Cave to be accumulated from different sources. Human activities are thought to have contributed the larger mammal specimens in the caves, representing dietary faunas. Most of the smaller mammal, bird and reptile remains likely came from disaggregated owl pellets, and a very small amount from kestrel pellets. Natural deaths may have also contributed to the remains (Veth et al., 2007). Veth. (1993) noted that at least part of the Noala and Hayne's Cave deposits were likely deposited by owl and Australian kestrel, Falco cenchroides, and that any open chambers in the region will likely have some contribution from these accumulating agents.

Similar non-anthropogenic accumulating agents contributed to the Morgan's Cave deposit. The most abundant species are rodents (Table 3). The most likely contributor of rodent remains to cave deposits in the north-west is Tyto alba, which is responsible for many bone accumulations in arid areas, using caves as roosts and nesting sites (Baynes and Jones, 1993; Veth et al., 2007; Baynes and McDowell, 2010). Tyto alba tend to follow rodent plagues, and can be nomadic, but if an area supports abundant prey for a long time, they will take up residence at single breeding site for generations (Andrews and Cook, 1990; Heywood and Pavey, 2002; McDowell, 2013). They usually swallow their prey whole, and regurgitate pellets containing bone with relatively little damage (Andrews and Cook, 1990; Kusmer, 1990; McDowell, 2013). The rodent material from Morgan's Cave is very fragmented, however, unlike a typical Barn Owl pellet deposit (Andrews and Cook, 1990; Kusmer, 1990; McDowell, 2013). Although the breakdown of owl pellets can cause the bones to become dispersed and increases fragmentation (Terry, 2004), the different feeding strategies of different species of owls may contribute to this.

Ninox species from the owl family Strigidae tend to leave more fragmented pellet material than the Tyto species, with mandible and dentaries broken and teeth alveoli worn from digestion, resulting in isolated teeth (Dodson and Wexlar, 1979; Andrews and Cook, 1990; Worthy and Holdaway,
1996). Their pellets would also break down, assisting with fragmentation (Terry, 2004). This is very similar to what is seen in Morgan's Cave. One contributor from the Strigidae family to the deposit could be Ninox connivens, as it would be large enough to take the larger marsupials such as Isoodon. Although uncommon, it is found in the Pilbara today, preferring wooded areas and mangroves over desert (Johnstone and Storr, 1998). Another possible contributor species is the smaller Ninox boobook. It currently occurs on Barrow Island, and while it does prefer wooded areas, it is found in deserts and islands off the west coast, usually over winter migrations (Johnstone and Storr, 1998). Bird eggshell has been found in the deposit, but Tyto alba, Ninox connivens, and Ninox boobook all have similar coloured eggs, making this an inadequate identifier of predator species.

Another predator of relevance is Macroderma gigas. These bats take small mammalian prey such as Pseudomys hermannsbugensis and Pseudomys nanus, (Diete et al., 2016), and tend to take prey to a roost to consume, particularly if there are young to feed. Prey is thoroughly consumed, with bones being chewed so finely that little remains to be identified in fecal matter (Douglas, 1967; Baynes and Baird, 1992). While the specimens from Morgan's Cave are fragmented, they are still mostly identifiable, making it less likely that if Macroderma was contributing to the deposit, it was a minor component compared to the owls.

The presence of larger-bodied marsupials such as Osphranter robustus, Petrogale lateralis, and Lagorchestes species could represent individuals who fell into the cave, particularly if it was similar to a pitfall cave (Veth 1993). They could have contributed to the fragmentation of the material by hopping over the owl pellet material, breaking it down further. However, it is unlikely that they are solely responsible for the breakage of the remains. The apparent lack of any cultural material suggests it is unlikely that the macropods were brought into the cave by humans.

\section{Biases in the Samples}

Two types of bias influence the mammal assemblage recovered from Morgan's Cave compared to the source palaeo-communities: accumulating agent bias, created by the predators that produced the assemblage (Behrensmeyer, 1991) and sampling bias, caused by the differential recovery of specimens due to the larger sieve mesh apertures used relative to the size of the faunal remains (Shaffer, 1992; Shaffer and Sanchez, 


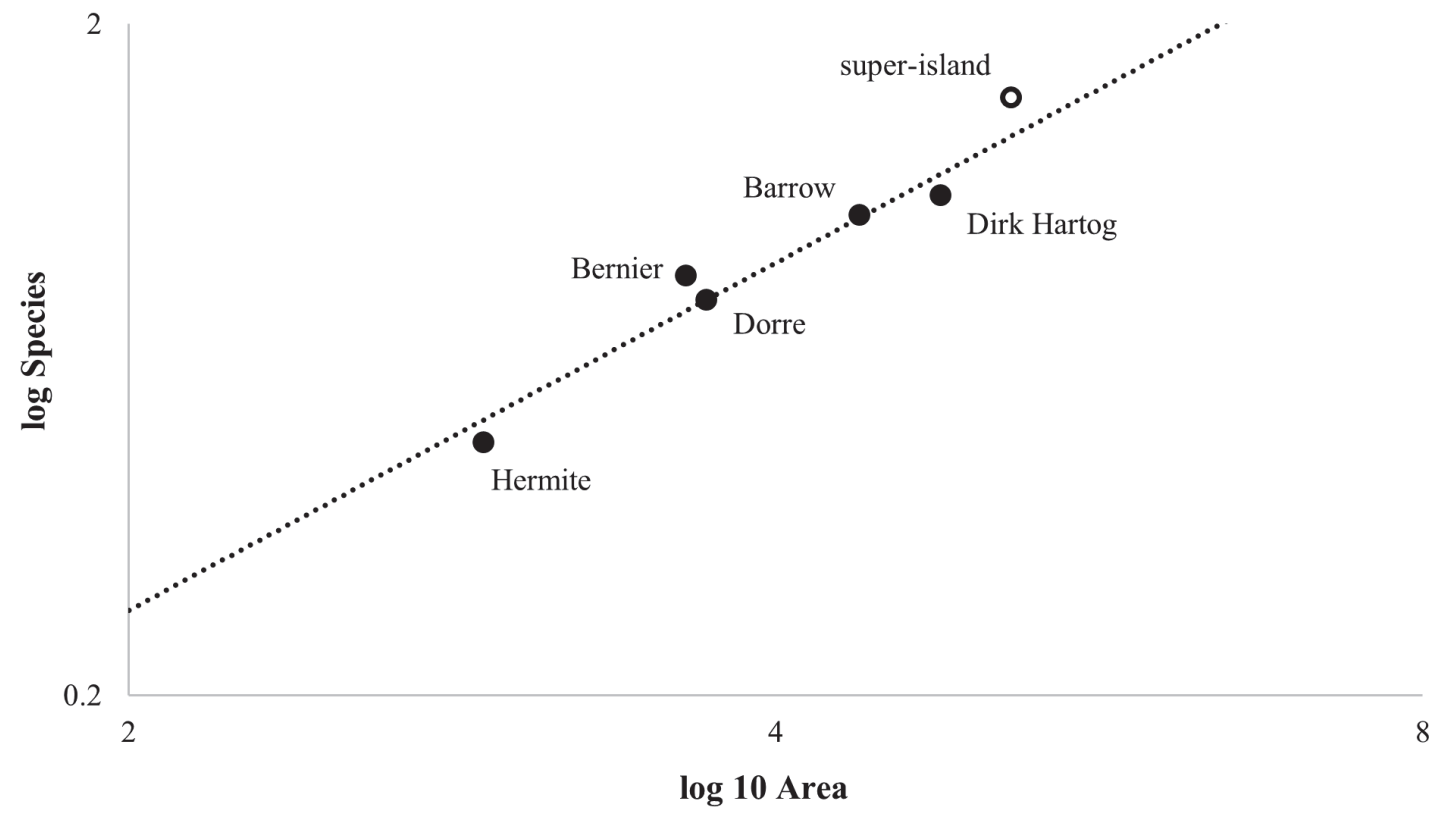

FIGURE 8. Log non-volant species vs log area plot for the north-west islands (filled circles) and the super-island at sea level $10 \mathrm{~m}$ below present (open circle).

1994; Lyman, 2012b; Baynes et al, 2019). These biases have also affected the Noala and Hayne's Cave samples. Owls and other accumulating agents, such as kestrels and bats, only hunt small animals, creating body size, age, and species biases (Andrews and Cook, 1990; Kusmer, 1990). Sampling bias was created by the use of a minimum $3 \mathrm{~mm}$ sieve. This was the standard small sieve used at the time, but it caused the differential loss of more remains of the smaller species, exacerbated by the fragmentation of the bones in the deposit. This effect is highlighted by the bulk sample of Barrow Island owl pellet material used for comparison, which has reduced relative abundance of larger bodied small mammal faunas such as Isoodon, as smaller specimens, such as Planigale sp, Pseudantechinus sp, Pseudomys nanus, and Zyzomys argurus, are retained in greater abundances (Figure 7).

\section{Palaeoenvironmental Interpretation}

These fossil mammalian faunas are diverse and nearly three times as rich in non-volant species currently found on Barrow Island. They include a number of sand plain specialists, indicating that the majority of the now-drowned landscape was arid and sandy (Veth et al., 2007). There are some species for which sandy substrates are not their principal habitat. These include Notomys longicaudatus (clays and clay loams), Pseudomys nanus and Rattus tunneyi (both found in bunch grasslands and savannah), P. fieldi (formerly non-sandy substrates with rocky ranges), and $P$. chapmani (stony substrates) (Veth et al., 2007). It is not unusual for this to occur on islands and could be due to competitive release, where some species expand their use of habitats they would not usually occupy (Abbott and Willis, 2016).

Veth et al. (2007) noted that the high abundance of sand plain specialists in Noala and Hayne's Caves deposits likely indicated the presence of extensive sand plain and sand dune environments. Less abundant clay-loam species and rock substrate specialists indicates a variety of habitats was also present among the sandy environments (Veth et al., 2007).

The sample to redundancy curve for Morgan's Cave (Figure 6) shows that despite reaching bedrock and ultrasonically cleaning the specimens, more species could potentially have been found if the deposit was deeper. Even with ultrasonic cleaning to recover as many specimens as possible, the graph has not quite reached an asymptote, suggesting that some species are not represented in the sample. Due to differential recovery and the fragmentation of the specimens, these species 
were not recovered on the sieves, and therefore are under-represented overall (Shaffer, 1992; James, 1997; Lyman, 2012b).

The most common species from Morgan's Cave (Figure 7) was a mix of sand plain specialists and non-sand plain species. This indicates that while sandy plains were the dominant landscape around Morgan's Cave, there was a variety of other habitats present that held the non-sand plain species. This finding supports the original interpretation made by Veth et al. (2007).

Some species disappear towards the top of the Morgan's Cave deposit, reflected in the spindle plot (Figure 7), which shows a decrease in sand plain specialists and an increase in some non-sand plain species. A change in the dominant landscape, as well as connectivity between suitable habitats, can be inferred from these patterns. Rising sea level and loss of coastal plain can be hypothesised as the main cause, especially as the number of species in the spindle plot declines over time. As the sea level rose, low-lying sand plains would have been slowly inundated, causing a decrease in suitable habitat for sand plain species, contributing to their decline. Areas of higher ground were comprised of calcarenite and would have been refuges for a longer period of time.

The spindle plots from the upper spits in Morgan's Cave record a transition of fauna dominated by sandy-plain substrate specialists, to the modern fauna recorded in the owl pellet deposit from Barrow Island (Figure 7), despite the impact of the Barrow Island bulk sample on relative abundances. This is consistent with the hypothesis of a change in sea level towards island formation resulting in an impact of reduced island area on the species present. Planigale and Pseudantechinus are present in high relative abundances in the Barrow Island owl pellet assemblage, whereas they are rare in the Morgan's Cave deposit. They still occur on Barrow Island (Abbott and Burbidge, 1995), and so were presumably present in the area before island formation. Their small numbers in Morgan's Cave, and their absence from Noala and Hayne's Caves, could be due to predator or sampling bias (Behrensmeyer, 1991; Lyman, 2012b). Hydromys chrysogaster is present in spits six, three, and two in Morgan's Cave, but is otherwise only found as a fossil in Noala Cave at the surface. Hydromys chrysogaster is locally found in coastal areas (Veth et al., 2007), and its presence in Morgan's Cave, and the possibility of the deposit being at least partially accumulated by Ninox connivens, a species that resides in mangrove environments, indicates a proximal coastline.

The decline in the relative abundances of many species to extinction and the morphing of the Morgan's Cave spindles into the frequencies observed for Barrow Island, is consistent with island formation as the major influence on species changes. We infer from this pattern that the Morgan's Cave deposit is younger than Hayne's Cave, which is dated at about 8.2 k.y.a. (Veth et al., 2007) and shows no decline in relative abundance. Veth et al. (2007) interpreted the abandonment of Hayne's Cave by humans as being due to rising seas and the distance of Campbell Island from the mainland. The effects of further sea level rise may be recorded in the Morgan's Cave deposit, continuing up to stabilisation at 7 k.y.a. (Lewis et al., 2013; Reeves et al., 2013) and possibly later given the accumulation vectors are not human. Insularisation, the loss of coastal plains and thus a decreasing area for terrestrial mammals to occupy (Lomolino and Weiser, 2001), appears to be the primary force of observed changes in the fauna of the island. By comparison, the effects of climate change are likely to have been minimal.

\section{The Species-area Relationship and the Montebello Islands}

The results suggest that loss of coastal plain area had the greatest impact on the non-volant mammal species from the Montebello Islands in the past, causing both changes in abundances and local extinctions.

Between 8.2 and 7.0 k.y.a., sea levels were rising to flood low-lying areas, and separated the Barrow and Montebello Islands from the mainland, with both areas being joined into one large island, which will be referred to as the super-island. For the purposes of analyses, this super-island is defined as the area created when the sea levels rose to less than $10 \mathrm{~m}$ below present (Figure 2). It could support a minimum of 33 non-volant mammal species (Figure 8), whereas the present-day fauna of Barrow Island only includes 11 non-volant mammals (Abbott and Burbidge, 2017; Moro and Lagdon, 2013). The super-island would have been sufficiently isolated so that new non-volant species could only colonise it by swimming or rafting, reducing immigration and the introduction of new terrestrial mammal species (Diamond, 1975; Laurance, 2010).

The Morgan's Cave deposit contains at least three times as many species as the Barrow Island fauna, so the land area available when the cave 


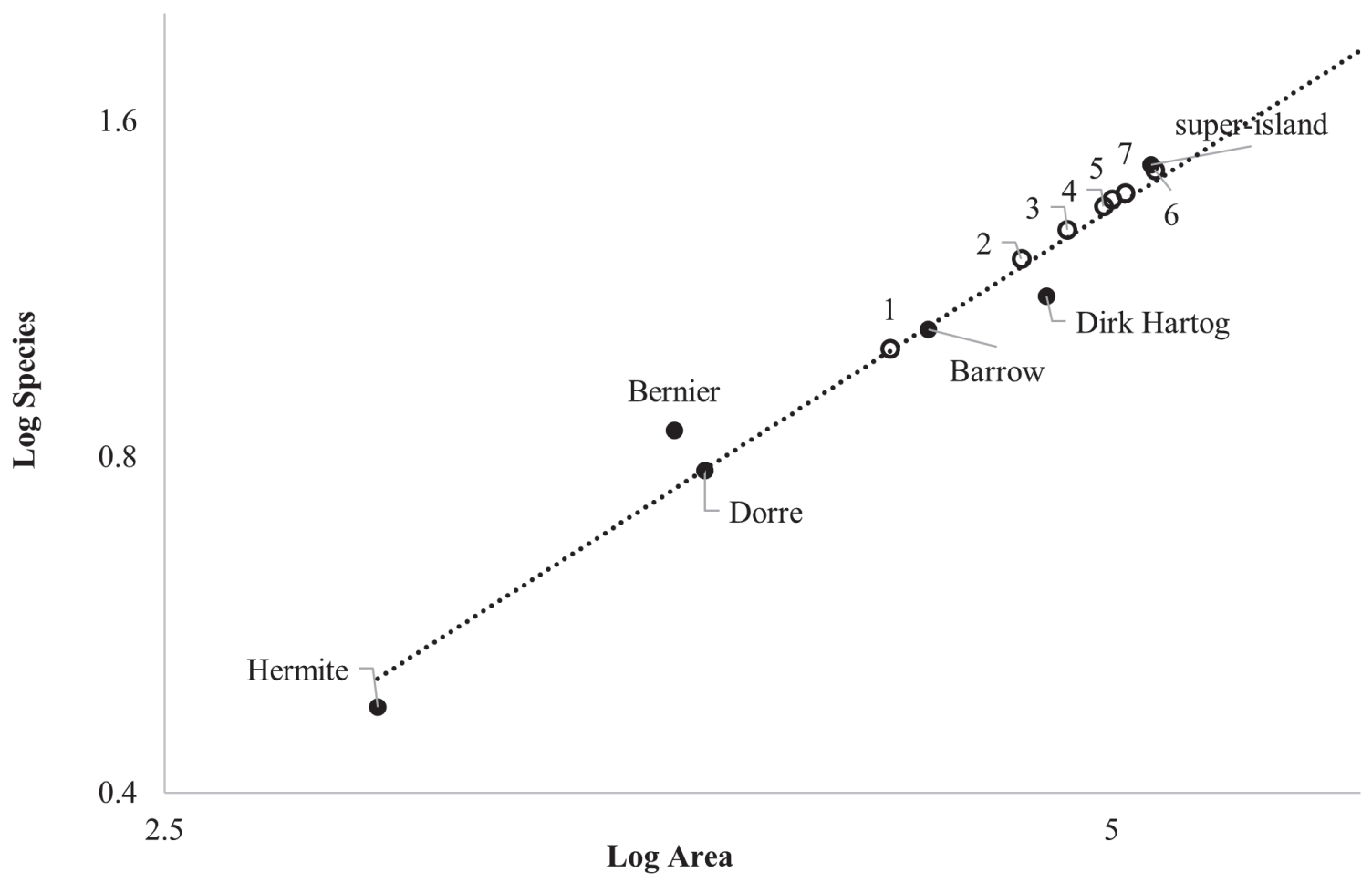

FIGURE 9. Species-area plot for islands on the north-west continental shelf (filled circles) (data from Abbott and Burbidge, 1995), and spits one to seven in Morgan's Cave (open circles).

deposit was forming must have been much larger. It was calculated from figure 2 of Veth et al. (2007) that when sea level was $10 \mathrm{~m}$ lower than present, the area of the super-island was about 140,000 ha, or seven times the size of Barrow Island $(20,200$ ha). Figure 8 shows that this estimated, enlarged area was still too small, however, for the full 33 non-volant species recorded from Morgan's Cave. Either the island area estimated is too small, the non-volant mammal fauna were already under pressure due to area limitations, or the accumulation of faunas began before 8.2 k.y.a. when the coastal plain was larger.

Archaeological evidence from Noala and Hayne's Caves suggests that humans abandoned both sites due to rising sea levels (Veth et al., 2007). The calibrated estimate for the deposition of Hayne's Cave is 8.2 k.y.a. This estimate puts it in a similar age range of island formation on Kangaroo Island, one of Australia's largest islands and another area that was attached to the mainland during times of low sea level from around 8.9 to 7.5 k.y.a. (Hope et al., 1977; McDowell et al., 2015; Bourman et al., 2016).

Once the super-island was isolated, its nonvolant mammal fauna would initially have been supersaturated, therefore every species could not survive. Extinction is not random. The species most likely to become extinct when an island is reduced in area are those that have a small geographical size range, low local abundance, ecological specialisation, large body size, slow life histories, high trophic level (Issac et al., 2009), are dependent on seasonal or patchy food sources, or go through drastic population fluctuations (Diamond, 1975). On the super-island, these species would have included $r$ life history strategists such as Notomys alexis and Pseudomys hermannsburgensis (Newsome and Corbett, 1975) that had fast breeding rates, and habitat specialists such as Notomys longicaudatus, likely explaining their decline in spits three to one of Morgan's Cave (Table 3; Figure 7). Medium-sized macropods, such as Lagorchestes hirsutus, L. conspicillatus, Osphranter sp. indet., and Petrogale lateralis, were affected due to their larger body size and their life history strategies. Lagorchestes hirsutus is a desert species and an $r$ life history strategist (Johnson and Burbidge, 2008). Petrogale lateralis is a slightly more $K$ life history strategist than species of Lagorchestes (Elridge and Pearson, 2008), enabling it to be better suited to island life. 


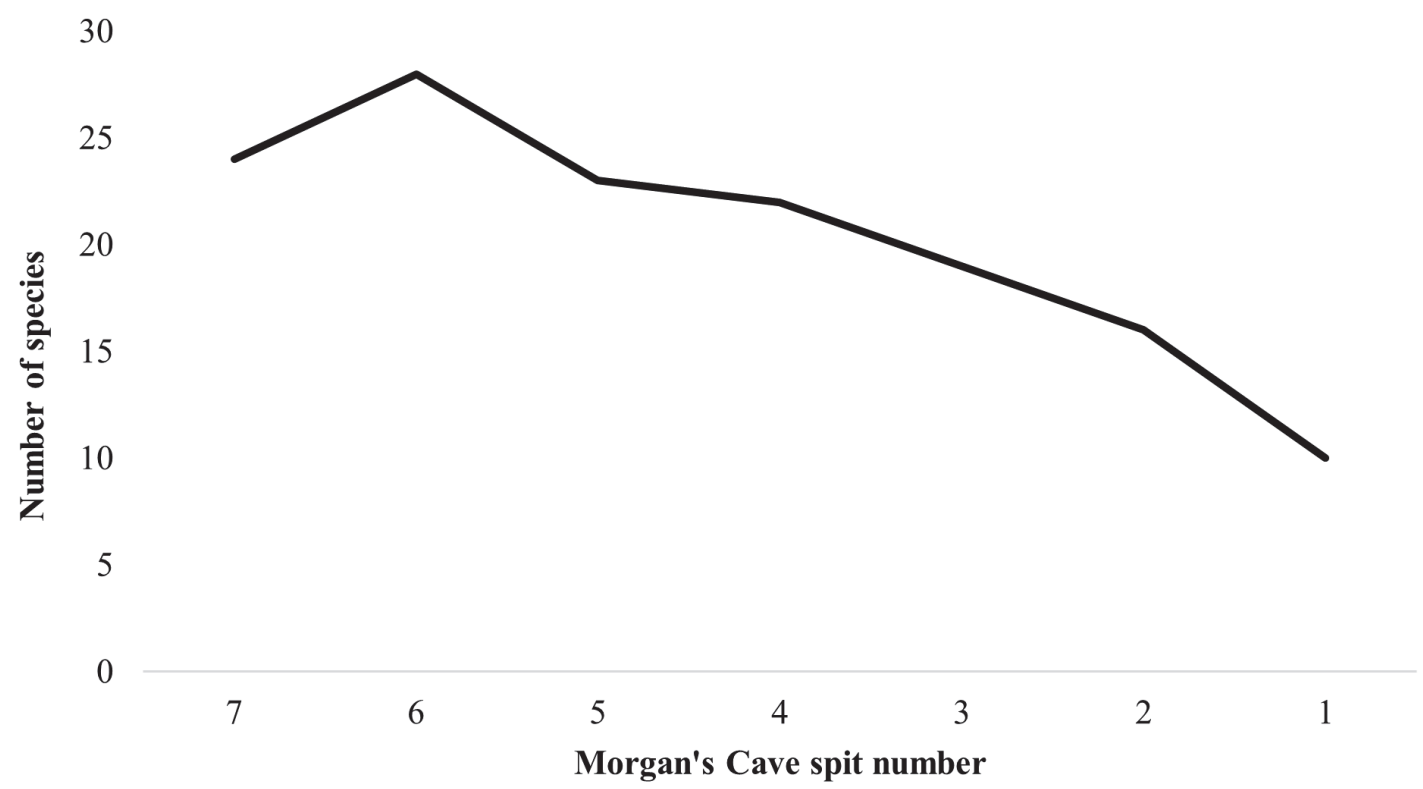

FIGURE 10. Number of species identified from each spit in Morgan's Cave, illustrating the increasing loss of species from spits four to one.

As sea level continued to rise and the superisland decreased in area, species were lost until Barrow Island finally supported only 11 non-volant species (Abbott and Burbidge, 1995). The rate of species loss would have increased on the Montebello Islands as they separated into separate, smaller islands, given that species are lost faster on smaller islands (Diamond, 1975; Laurance, 2010). Hermite Island is the largest of the Montebello Islands at 836 ha (Figure 9) and historically supported Isoodon auratus, Lagorchestes conspicillatus, and Hydromys chrysogaster (Abbott and Burbidge, 1995). These species were not lost from Hermite Island due to the small island effect, where species on islands below a certain area threshold can be affected by stochastic events more than island area (Lomolino, 2000; Lomolino and Weiser, 2001).

The minimum area for the number of species present in each spit in Morgan's Cave can be estimated using the species-area formula: $S=\mathrm{cA}^{\mathrm{z}}$ (e.g., Losos and Parent, 2010). Figure 9 compares the number of species known on islands off the north-west coast of Australia (Abbott and Burbidge, 1995) with the data from Morgan's Cave, including the super-island estimate. It shows that when spits seven to four in Morgan's Cave were deposited, the land area around the cave was still quite large, greater than that of present-day Dirk Hartog Island, and similar to the area of the super-island; although a small decrease in the number of species can be detected could potentially be due to sampling bias. As sea level rose through time, however, that area became smaller, and the rate of species loss increased. The island assemblage continued to lose species as reflected in the data trends from spits three to one (Figure 10).

The STR curve (Figure 5) shows that more samples could have been drawn from Morgan's Cave to yield more results; there is an underestimate in the number of non-volant mammal species in the Morgan's Cave deposit. The predator bias created by the accumulation of the deposit by owls and potentially bats means some species appear to be absent from the fauna, as they do not fit the prey criteria of the accumulating predators. There is also a sampling bias in the fauna; small species would have not been retained in the $3 \mathrm{~mm}$ sieves used to process the Morgan's Cave samples. High degrees of fragmentation may have suppressed the number of identifiable species. The differential loss of smaller species through these taphonomic and sampling biases best explains the underestimate shown in the STR.

As area estimates were calculated from the number of non-volant mammal species recovered, area calculations will thus have an error factor. However, since this error is consistent throughout the depth of the deposit, valid comparisons can be 
made between spit assemblages from the Morgan's Cave deposit.

\section{Conclusions and Implications for Future Research}

The fossil mammal faunal assemblages recovered from Morgan's Cave are not due to human activity, and instead are derived from predation by owls and/or bats, and possibly pitfall. Despite this difference in accumulation agent, they share similarities with those described from excavations of sites occupied by humans at Noala and Hayne's Caves from the Montebello Islands. Morgan's Cave provides evidence of a pattern of decreasing species richness through time which is thought to reflect island formation through multiple stages (Figure 10). A progression is shown from when the Montebello Islands were part of the mainland, to becoming a super-island (with Barrow Island) with sea levels rising to approximately -10 $\mathrm{m}$. Finally, at full high sea stand the contemporary outline of the islands sees accelerated loss of species (Figure 9). Species shifts reflect habitat change, from largely sand plain and dune environments to predominately rock and loam island substrates (Figure 7). The Morgan's Cave assemblage likely continued to accumulate until after 8 or 7 k.y.a., by which time humans had abandoned both the Montebello and Barrow Islands.

This current analysis of the fauna from the Morgan's Cave study is consistent with the findings by Veth et al. (2017) on the combined anthropogenic and natural contributions made to the Boodie
Cave deposits on Barrow Island. It also helps document the history of the composition of the mammal fauna found currently on Barrow Island, an important A-Class Nature Reserve (Moro and Lagdon, 2013). Increased knowledge about the historic composition of the dominant faunas and larger island biogeographic processes provides necessary information for successful management of offshore conservation estates.

\section{ACKNOWLEDGEMENTS}

A. Baynes, J. O'Shea, and H. Mills supervised the Honours thesis by Piper and are warmly thanked for their guidance and inputs. We are grateful to A. Baynes for ongoing assistance with identifications of rodents and small mammals during the completion of the Honours project by Piper. M. Siversson and L. Umbrello are acknowledged for providing access to Western Australian Museum collection reference material. E. Webb, P. Kendrick, and A. Baynes are thanked for providing helpful comments on a first draft of this paper. Ian Abbott provided subsequent comments and suggestions. J. Barteaux is thanked for support while using the Archaeology Laboratory at the University of Western Australia and ongoing storage of specimens.

The original research was carried out by $P$. Veth and colleagues from University of Western Australian, James Cook University and Australian Institute of Aboriginal and Torres Strait Islander Studies.

\section{REFERENCES}

Abbott, I. and Burbidge, A.A. 1995. The occurrence of mammal species on the islands of Australia: a summary of existing knowledge. CALM Science, 1:259-324.

Abbott, I. and Wills, A. 2016. Review and synthesis of knowledge of insular ecology, with emphasis on the islands of Western Australia. Conservation Science Western Australia, 11:1-209.

Abbott, I. and Burbidge A.A. 2017. Mammals on Western Australian islands: occurrence and preliminary analysis. Australian Journal of Zoology, 65(3):183-195. https://doi.org/10.1071/ZO17046

Anderson, D.E., Goudie, A.S., and Parker, A.G. 2013. Global environments through the Quaternary: exploring environmental change. Second Edition. Oxford University Press, Oxford.

Andrews, P. and Cook, J. 1990. Owls, caves and fossils: predation, preservation and accumulation of small mammal bones in caves, with analysis of the Pleistocene cave faunas from Westbury-sub-Mendip, Somerset UK. University of Chicago Press, Chicago.

Arrhenius, O. 1921. Species and area. Journal of Ecology, 9(1):95-99. https://doi.org/10.2307/2255763 
Barnosky, A.D., Carrasco, M.A., and Davis, E.B. 2005. The impact of species-area relationship on estimates of palaeodiversity. PLoS Biology, 3:e266. https://doi.org/10.1371/journal.pbio.0030266

Baynes, A. 1979. The analysis of a late Quaternary mammal fauna from Hastings Cave, Jurien. Unpublished PhD Thesis, University of Western Australia, Perth, Western Australia, Australia.

Baynes, A. and Baird, R.F. 1992. The original mammal fauna and some information on the original bird fauna of Uluru National Park, Northern Territory. Rangeland Journal, 14:92-106. https://doi.org/10.1071/rj9920092

Baynes, A. and Jones, B. 1993. The mammals of Cape Range peninsula, north-western Australia. Records of the Western Australian Museum Supplement, 45:207-225.

Baynes, A. and McDowell, M.C. 2010. The original mammal fauna of the Pilbara biogeographic region of north-western Australia. Records of the Western Australian Museum Supplement, 78(1):28,5-298. https://doi.org/10.18195/issn.0313-122x.78(1).2010.285-298

Baynes, A., Piper, C.J., and Thorn, K.M. 2019. An experimental investigation of differential recovery of native rodent remains from Australian palaeontological and archaeological deposits. Records of the Western Australian Museum, 34(1):1-28. https://doi.org/10.18195/issn.0312-3162.34(1).2019.001-030

Behrensmeyer, A.K. 1991. Terrestrial vertebrate accumulations, p. 291-335. In Allison, P.A. and Briggs, D.E.G. (eds.), Taphonomy: Releasing the Data locked in the Fossil Record. Plenum Press, New York.

Bilney, R.J., Cooke, R., and White, J.G. 2010. Underestimated and severe: small mammal decline from the forests of south-eastern Australia since European settlement, as revealed by a top-order predator. Biological Conservation, 143(1):52-59. https://doi.org/10.1016/j.biocon.2009.09.002

Bilney, R.J. 2012. A reassessment of the predator responsible for Wakefield's 'native cat den' sub-fossil deposits in the Buchan district: sooty owl, not eastern quoll. Victorian Naturalist, 129(4):138-143.

Birks, H.J.B. 1996. Contributions of Quaternary palaeoecology to nature conservation. Journal of Vegetation Science, 7:89-98. https://doi.org/10.2307/3236420

Bourman, R.P., Murray-Wallace, C.V., and Harvey, N. 2016. Coastal landscapes of South Australia. University of Adelaide Press, Adelaide. https://doi.org/10.20851/coast-sa

Burbidge, A.A., Blyth, J.D., Fuller, P.J., Kendrick, P.G., Stanley, F.J., and Smith, L.A. 2000. The terrestrial vertebrate fauna of the Montebello Islands, Western Australia. CALM Science, 3:95-107.

Davis, M.B. and Shaw R.G. 2001. Range shifts and adaptive responses to Quaternary climate change. Science, 292:673-679. https://doi.org/10.1126/science.292.5517.673

Denniston, R.F., Asmerom, Y., Lachniet, M., Polyak, V.J., Hope, P., An, N., Rodzinyak, K., and Humphreys, W.F. 2013. A Last Glacial Maximum through middle Holocene stalagmite record of coastal Western Australia climate. Quaternary Science Reviews, 77(1):101-112. https://doi.org/10.1016/j.quascirev.2013.07.002

Diamond, J.M. 1975. The island dilemma: lessons of modern biogeographic studies for the design of natural reserves. Biological Conservation, 7(2):129-146. https://doi.org/10.1016/0006-3207(75)90052-X

Diete, R.L., Dixon, K.M., and Barden, P.A. 2016. Predation of pitfall-trapped rodents by the ghost bat, Macroderma gigas. Australian Mammology, 38(2):249-252. https://doi.org/10.1071/AM15022

Dodson, P. and Wexlar, D. 1979. Taphonomic investigations of owl pellets. Paleobiology, 5(3):275-284. https://doi.org/10.1017/s0094837300006564

Douglas, A.M. 1967. The natural history of the ghost bat, Macroderma gigas (Microchiroptera, Megadermatidae), in Western Australia. The Western Australian Naturalist, 10:125-138.

Elridge, M.D.B. and Pearson, D.J. 2008. Black-footed Rock-wallaby Petrogale lateralis Gould 1842, p. 376-380. In Van Dyck, S. and Straham, R. (eds.), The Mammals of Australia. New Holland Publishers Pty Ltd., Australia.

Gibbard, P.L. and van Kolfschoten, T. 2004. The Pleistocene and Holocene epochs, p. 441-453. In Gradstein, F.M., Ogg, J.G., and Smith, A.G. (eds.), A Geologic Time Scale. Cambridge, Cambridge University Press. 
Gibson, L.A. 2014. Biogeographic patterns on Kimberley islands, Western Australia. Records of the Western Australian Museum Supplement, 81:245-280. https://doi.org/10.18195/issn.0313-122x.81.2014.255-280

Gotelli, N.J. and Colwell, R.K. 2001. Quantifying biodiversity: procedures and pitfalls in the measurement and comparison of species richness. Ecology Letters, 4:379-391. https:// doi.org/10.1046/j.1461-0248.2001.00230.x

Hammer, Ø., Harper, D.A.T., and Ryan, P.D. 2001. PAST: Paleontological Statistics Software Package for Education and Data Analysis. Palaeontologia Electronica, 4.1.4A:1-9. http://palaeo-electronica.org/2001_1/past/issue1_01.htm

Hays, J.D., Imbrie, J., and Shackleton, N.J. 1976. Variations in the earth's orbit: pacemaker of the ice ages. Science, 194(4270):1121-1132. https://doi.org/10.1126/science.194.4270.1121

Heywood, M.R. and Pavey, C.R. 2002. Relative importance of plague rodents and dasyurids as prey of barn owls in central Australia. Wildlife Research, 29(2):203-207. https://doi.org/10.1071/wr01104

Hickman, A.H. and Strong, C.A. 2003. Dampier - Barrow Island, W. A. (2nd Edition): Western Australia Geological Survey, 1:250,000 geological series map and explanatory notes. Optima Press, Perth, Western Australia.

Hill, F.L. 1955. Notes on the natural history of the Monte Bello Islands. Proceedings of the Linnean Society of London, 165(2):113-124. https://doi.org/10.1111/j.1095-8312.1955.tb00724.x

Hocking, R. M., Moors, H.T., and van de Graaff, W.J.E. 1987. Geology of the Carnarvon Basin, Western Australia. Geological Survey of Western Australia Bulletin No. 133:1-289.

Hope, J.H., Lampert, R.J., Edmondson, E., Smith, M.J., and van Tets, G.F. 1977. Late Pleistocene remains from Seton rock shelter, Kangaroo Island, South Australia. Journal of Biogeography, 4(4):363-385. https://doi.org/10.2307/3038194

Issac, J.L., Vanderwal, J., Johnson, C.N., and Williams, S.E. 2009. Resistance and resilience: quantifying relative extinction risk in a diverse assemblage of Australian tropical rainforest vertebrates. Diversity and Distributions, 15:280-288. https://doi.org/10.1111/j.1472-4642.2008.00531.x

James, S.R. 1997. Methodological issues concerning screen size recovery rates and their effects on archaeofaunal interpretations. Journal of Archaeological Science, 24:385-397. https://doi.org/10.1006/jasc.1996.0123

Johnson, K.A. and Burbidge, A.A. 2008. Rufous Hare-wallaby Lagorchestes hirsutus Gould 1844, p. 317-319. In van Dyck, S. and Straham, R. (eds.), The Mammals of Australia. New Holland Publishers Pty Ltd, Australia.

Johnstone, R.E. and Storr, G.M. 1998. Handbook of Western Australian birds: Volume I. Western Australian Museum, Perth, Western Australia.

Kusmer, K.D. 1990. Taphonomy of owl pellet deposition. Journal of Paleontology, 64:629-637. https://doi.org/10.1017/s0022336000042669

Laurance, W.F. 2010. Beyond island biogeography theory: understanding habitat fragmentation in the real world, p. 214-236. In Losos, J.B. and Ricklefs, R.E. (eds.), The Theory of Island Biogeography Revisited. Princeton University Press, New Jersey. https://doi.org/10.1515/ 9781400831920.214

Lewis, S.E., Sloss, C.R., Murray-Wallace, C.V., Woodroffe, C.D., and Smithers, S.G. 2013. Postglacial sea-level changes around the Australian margin: a review. Quaternary Science Reviews, 74:115-138. https://doi.org/10.1016/j.quascirev.2012.09.006

Lomolino, M.V. 2000. Ecology's most general, yet protean pattern: the species-area relationship. Journal of Biogeography, 27:17-26. https://doi.org/10.1046/j.1365-2699.2000.00377.x

Lomolino, M.V. and Weiser, M.D. 2001. Towards a more general species-area relationship: diversity on all islands, great and small. Journal of Biogeography, 28:431-445. https://doi.org/10.1046/j.1365-2699.2001.00550.x

Losos, J.B. and Parent, C.E. 2010. The species-area relationship, p. 415-438. In Losos, J.B. and Ricklefs, R.E. (eds.), The Theory of Island Biogeography Revisited. Princeton University Press, New Jersey. https://doi.org/10.1515/9781400831920.415

Lyman, R.L. 2006. Paleozoology in the service of conservation biology. Evolutionary Anthropology: Issues, News and Reviews, 15:11-19. https://doi.org/10.1002/evan.20083

Lyman, R.L and Ames, K.M. 2004. Sampling to redundancy in zooarchaeology: lessons from the Portland Basin, north-western Oregon and south-western Washington. Journal of Ethnobiology, 24:329-346. https://doi.org/10.1016/j.jasrep.2015.12.020 
Lyman, R.L. and Ames, K.M. 2007. On the use of species-area curves to detect the effects of sample size. Journal of Archaeological Science, 34:1985-1990. https://doi.org/10.1016/j.jas.2007.01.011

Lyman, R.L. 2012a. Biodiversity, paleozoology and conservation biology, p. 147-169. In Louys, J. (ed.), Paleontology in Ecology and Conservation. Springer-Verlag, Berlin. https://doi.org/10.1007/978-3-642-25038-5_8

Lyman, R.L. 2012b. The influence of screen mesh size, and size and shape of rodent teeth on recovery. Journal of Archaeological Science, 39:1854-1861. https://doi.org/10.1016/j.jas.2012.01.027

Mannion, P.D., Upchurch, P., Benson, R.B.J., and Goswami, A. 2014. The latitudinal biodiversity gradient through deep time. Trends in Ecology and Evolution, 29:42-50. https://doi.org/10.1016/j.tree.2013.09.012

Mayhew, P.J., Bell, M.A., Benton, T.G., and McGowan, A.J. 2012. Biodiversity tracks temperature over time. Proceedings of the National Academy of Sciences of the United States of America, 109:15141-15145. https://doi.org/10.1073/pnas.1200844109

McDowell, M.C. 2013. Late Quaternary faunal response to environmental change and isolation on a large Australian land-bridge island. Unpublished PhD thesis, Flinders University of South Australia, Adelaide, Australia.

McDowell, M.C., Prideaux, G.J., Walshe, K., Bertuch, F., and Jacobsen, G.E. 2015. Reevaluating the late Quaternary fossil mammal assemblage of Seton rock shelter, Kangaroo Island, South Australian, including evidence for late-surviving megafauna. Journal of Quaternary Science, 30:355-364. https://doi.org/10.1002/jqs.2789

Mills, H.R., Moro, D., and Spencer, P.B.S. 2004. Conservation significance of island versus mainland populations: a case study of dibblers (Parantechius apicalis) in Western Australia. Animal Conservation, 7:387-395. https://doi.org/10.1017/s1367943004001568

Mitchell, J., Peacock, E., and Myatt, S. 2016. Sampling to redundancy in an applied zooarchaeology: a case study from a freshwater shell ring in the Mississippi Delta, southeastern USA. Journal of Archaeological Science: Reports 5:499-508. https://doi.org/10.1016/j.jasrep.2015.12.020

Moro, D. and Lagdon, R. 2013. History and environment of Barrow Island. Records of the Western Australian Museum Supplement, 83:1-8. https://doi.org/10.18195/issn.0313-122x.83.2013.001-008

Morse, K. 1993. Who can see the sea? Prehistoric aboriginal occupation of the Cape Range peninsula. Records of the Western Australian Museum Supplement, 45:227-242.

Newsome, A.E. and Corbett, L.K. 1975. Outbreaks of rodents in semi-arid and arid Australia: causes, preventions, and evolutionary considerations, p. 117-153. In Prakash, I. and Ghosh, P.K., (eds.), Rodents in Desert Environments. Springer, Netherlands. https://doi.org/10.1007/978-94-010-1944-6_6

Pearson, S. and Dodson, J.R. 1993. Stick-nest rat middens as sources of palaeoecological data in Australian deserts. Quaternary Research, 39:347-354. https://doi.org/10.1006/qres.1993.1041

Pearson, S., Lawson, E., Head, L., McCarthy, L., and Dodson, J. 1999. The spatial and temporal patterns of stick-nest rat middens in Australia. Radiocarbon, 41:295-308. https://doi.org/10.1017/s0033822200057155

Pickett, E. J. 1997. The late Pleistocene and Holocene vegetation history of three lacustrine sequences from the Swan Coastal Plain, southwestern Australia. Unpublished Ph.D. thesis, University of Western Australia, Perth, Western Australia, Australia.

Pokines, J.T., Nowell, A., Bisson, M.S., Cordova, C.E., and Ames, C.J. H. 2011. The functioning of a natural fauna trap in a semi-arid environment: preliminary investigations of WZM-1, a limestone sinkhole near Wadi Zarpa Ma'in, Hashemite Kingdom of Jordan. Journal of Taphonomy, 9:89-115.

Przywolnik, K. 2005. Long term transitions in hunter-gatherers of coastal north-western Australia, p. 117-205. In Veth, P.M., Smith, P., and Hiscock, P. (eds.), Desert Peoples: Archaeological Perspectives. Blackwell Publishing, Oxford. https://doi.org/10.1002/9780470774632.ch10

Reeves, J.M., Bostock, H.C., Ayliffe, L.K., Barrows, T.T., De Deckker, P., Devriendt, L.S., Dunbar, G.B., Drysdale, R.N., Fitzsimmons, K.E., Gagan, M.K., Griffiths, M.L., Haberle, S.G., Jansen, J.D., Krause, C., Lewis, S., McGregor, H.V., Mooney, S.D., Moss, P., Nanson, G.C., Purcell, 
A., and van der Kaars, S. 2013. Palaeoenvironmental change in tropical Australasia over the last 30,000 years - a synthesis by the OZ-INTIMATE group. Quaternary Science Reviews, 74:97-114. https://doi.org/10.1016/j.quascirev.2012.11.027

Rial, J.A., Oh, J., and Reischmann, E. 2013. Synchronization of the climate system to eccentricity forcing and the 100,000-year problem. Nature Geoscience, 6:289-293. https://doi.org/10.1038/ngeo1756

Shaffer, B.S. 1992. Quarter-inch screening: understanding biases in recovery of vertebrate faunal remains. American Antiquity, 57:129-136. https://doi.org/10.2307/2694839

Shaffer, B.S. and Sanchez, J.L.J. 1994. Comparison of 1/8"- and 1/4"-mesh recovery of controlled samples of small-to-medium-sized mammals. American Antiquity, 59:525-530. https://doi.org/10.2307/282464

Terry, R.C. 2004. Owl pellet taphonomy: A preliminary study of the post-regurgitation taphonomic history in a temperate forest. Palaios, 19:497-506. https://doi.org/10.1669/0883-1351(2004)019<0497:optaps>2.0.co;2

Terry, R.C. 2010. The dead do not lie: using skeletal remains for rapid assessment of historical small-mammal community baselines. Proceedings of the Royal Society, 277:1193-1201. https://doi.org/10.1098/rspb.2009.1984

Van de Graaff, W.J.E., Denman, P.D., and Hocking, R.M. 1982. Onslow W. A.: Western Australia Geological Survey, 1:250,000 geological series map and explanatory notes. Perth, Western Australia.

Van Dyck, S. and Strahan, R. 2008. The Mammals of Australia, Third Edition. Reed New Holland Publishing, Sydney.

Vegas-Vilarrúbia, T., Rull, V., Montoya, E., and Safont, E. 2011. Quaternary palaeoecology and nature conservation: a general review with examples from the neotropics. Quaternary Science Reviews, 30:2361-2388. https://doi.org/10.1016/j.quascirev.2011.05.006

Veth, P. 1993. The Aboriginal occupation of the Montebello Islands, northwest Australia. Australian Aboriginal Studies, 2:39-50.

Veth, P. 1995. Aridity and settlement in northwest Australia. Antiquity, 69:733-746. https://doi.org/10.1017/s0003598x00082302

Veth, P., Aplin, K., Wallis, L., Manne, T., Pulsford, T., White, E., and Chappell, A. 2007. The archaeology of Montebello Islands, north-west Australia: late Quaternary foragers on an arid coastline. British Archaeological Reports International Series, 1668:1-84. https://doi.org/ 10.30861/9781407301037

Veth, P., Ward, I., Manne, T., Ulm, S., Ditchfield, K., Dortch, J., Hook, F., Petchey, F. Hogg, A. Questiaux, D., Demuro, M., Arnold, L., Spooner, N., Levchenko, V., Skippington, J., Byrne, C., Basgall, M., Zeanah, D., Belton, D., Helmholz, P., Bajkan, S., Bailey, R., Placzek, C., and Kendrick, P. 2017. Early human occupation of a maritime desert, Barrow Island, north-west Australia. Quaternary Science Reviews, 168:19-29. https://doi.org/10.1016/j.quascirev.2017.05.002

Williams, M.A.J. 1993. Quaternary Environments. Edward Arnold, London.

Williams, J.W., Blois, J.L., and Shuman, B.N. 2011. Extrinsic and intrinsic forcing of abrupt ecological change: case studies from the late Quaternary. Journal of Ecology, 99:664-677. https://doi.org/10.1111/j.1365-2745.2011.01810.x

Worthy, T.H. and Holdaway, R. 1996. Taphonomy of two Holocene microvertebrate deposits, Takaka Hill, Nelson, New Zealand, and identification of the avian predator responsible. Historical Biology, 12:1-24. https://doi.org/10.1080/08912969609386551 